\title{
Gaming as pedagogy in the linguistics classroom
}

\author{
Andrew McKenzie \& Jeffrey Punske*
}

\begin{abstract}
We explore how content-driven games may be utilized to enhance linguistics pedagogy in the classroom. We explore three games created by the authors for in-class play. The games involve semantics: Eventuality (about aspect/Aktionsart), $\mathrm{f}(\mathrm{x})$ (lambda-calculus); and syntax: Parameters. We discuss the major skills developed by the games and the best practices for designing games for in-class use. We focus on four elements in the talk: player interaction, randomization, process training, and entertainment.
\end{abstract}

Keywords. teaching lingustics; pedagogy; gaming

1. Gaming in the classroom. This paper describes efforts the authors have made to introduce games directly into linguistics pedagogy in advanced courses. The games integrate course material and lessons and focus on building analytical skills while entertaining the learner. In this short paper, we examine how linguistics pedagogy and outreach may be improved through the use of games. We focus primarily on three instructor-developed games: $f(x)$, Eventuality, and Parameters. We discuss the design principles of each game and how they align with core principles of linguistics pedagogy, so as to provide a roadmap for others who may wish to develop such games. We also examine other commercially available games constructed specifically around linguistic concepts, along with adaptions of familiar games for pedagogical purposes.

1.1. Motivations. The use of games in the classroom mainly involves improving the rote memorization process for facts or for analytic techniques. In a game set-up, students can enjoy running through drills. It also trains in processes and makes problem sets more realistic. A well-constructed game stands out from other lessons, and prominence aids memory.

Also, students are used to playing board games, ever more so now during an unprecedented boom in social board gaming. Learners can bootstrap off of gaming structures to construct their knowledge. Shultz Colby (2017: 55) highlights the value of games precisely "because they are multimodal systems with their own active genre ecologies."

1.2. DESIGN PRINCIPLES. The construction of the games follows a set of design principles. The first is player interaction: The students engage each other, sharing knowledge, assisting each other's learning, and building cohesion in the group. Some students also gain experience in academic leadership helping others.

The second is process training. Instead of simply teaching facts or concepts to memorize, the games incorporate analytic processes into the gameplay. Students practice doing linguistics, and through repetitive action can internalize the steps of the process.

The third is randomization, exposing students to new problems to solve every time in a way that mimics how linguists encounter data in the real world. The students have to figure

*Thanks go to audiences at the University of Kansas, the University of Massachusetts-Amherst,, Southern Illinois University, and the LSA Annual Meeting. Authors: Andrew McKenzie, University of Kansas (andrew.mckenzie@ku.edu) \& Jeffrey Punske(punske@siu.edu). 
out how to deal with what is dealt them. Sometimes, problems are unsolvable, and students gain experience recognizing and handling such scenarios.

The fourth is entertainment. Without fun, the exercise is a glorified problem set, and hardly worth the extra work. Botturi \& Loh (2009) point out that many instructors neglect to ensure an element of fun in their classroom games, but playability makes the process more interesting. Also, the game itself can add a twist of strategy to engage students' thinking. Most students are very familiar with playing board games, so we try to build off of those habits to incorporate lessons.

These principles have to be put into place under the constraint of class structure. Consequently, the games are designed to be playable in short amounts of time so that the students can learn them quickly and enjoy them during one class session. To achieve these more successfully, we make "Euro-style" games, which emphasize playability, ease of learning, and friendly competitivity throughout the game. The gameplay ensures that every player is still in the game until the end, and prevents any one player from running away with the victory. The games often involve a story-telling conceit that creates a setting for the game and helps immerse the players in their tasks. For instance, the game Ticket to Ride involves building a railroad network across the 19th century US, and the artwork of the game reflects the conceit.

The games can be more or less competitive, depending in part on the conceit. Some games are fully cooperative, like the popular Pandemic, where the players team up to fight spreading diseases, and the players win or lose together.

2. Design principles in action. This section will discuss three games in terms of the design principles and how they're applied. The games are at different stages of development, allowing for a peek at the game-making process.

2.1. DEVELOPED AND REFINED. $F(x)$ (read: $\mathrm{f}$ of $\mathrm{x}$ ) is a three-or-four player game that practices the $\lambda$-calculus in a typed semantics, for use in a course in formal semantics. It is a card game, where players earn points by saturating $\lambda$-expressions and moving pieces around a game board. Designed as a Euro-style game, its conceit is that the players are travelling home from a medieval fair, but a washed-out bridge necessitates a lengthy detour (in the shape of a lambda, Fig. 3). To gain points, players must collect value conditions of $\lambda$-expressions by plugging in argument cards properly, and the first player home wins more points. The game takes around 25 minutes to play, so in a $75-$ minute class the students can learn it and repeat it, sometimes twice.

The game exemplifies the design principles in clear ways:

1. Player Interaction The players are not teamed up unless by choice, but they can play cooperatively and help each other with the $\lambda$-expressions, by explaining processes to one another. They can also play competitively by surveilling opponents to ensure that they are doing the exercise properly.

2. Process Training The key process of the game is the $\beta$-reduction component of the $\lambda$ calculus. Given a hand of argument cards, they work on organizing the expressions and saturating them in order, over and over. When it comes to formal semantics, practice makes perfect (Fig. 2). 


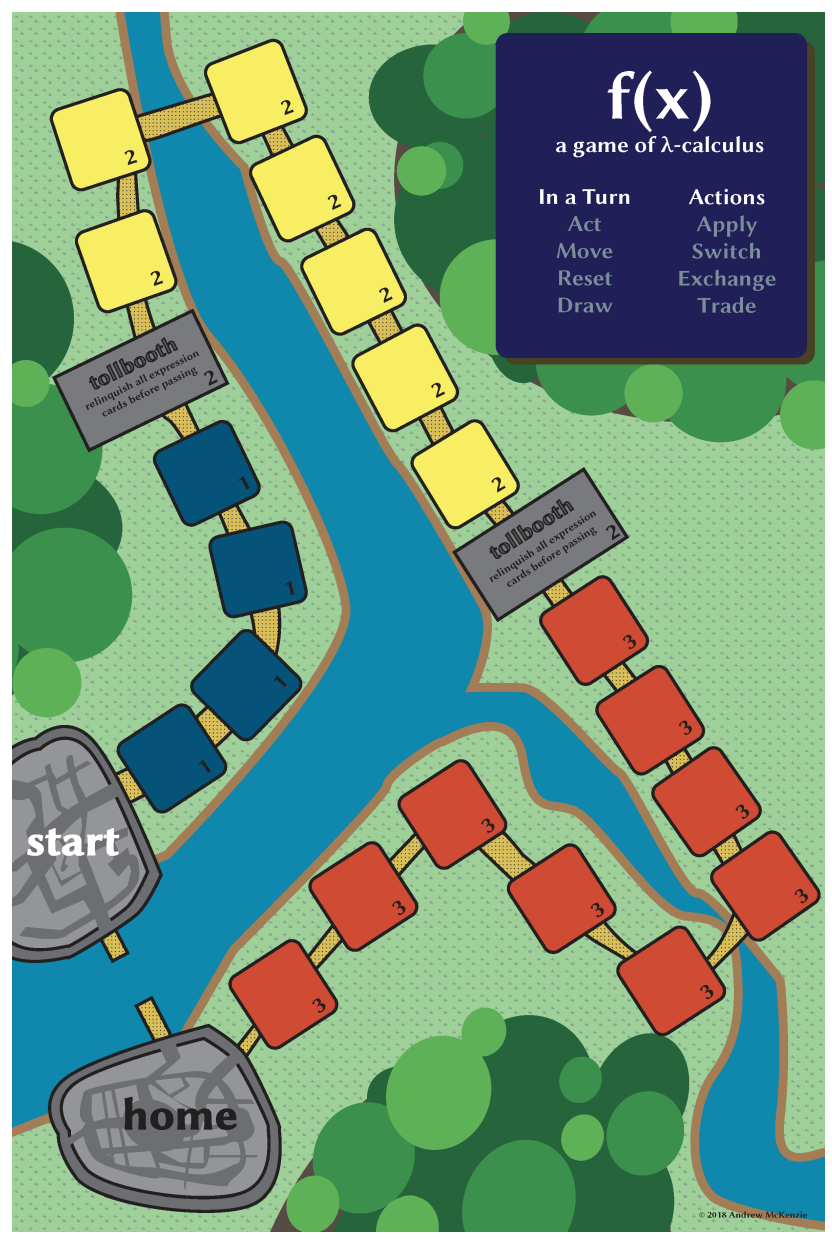

Figure 1: The gameboard for $f(x)$ (printed on $11 \times 17$ )

3. Randomization The arguments and $\lambda$-expressions come from cards, so the problem set is different every time and constantly changing. Sometimes students cannot saturate anything, and must conduct other actions. They can also manipulate the arguments to create workable expressions.

4. Entertainment For each turn, players choose two out of a set of actions helpfully printed on the board, and must strategize independently of the problem solving. The artwork and details give the sense of a 'real' game, and the competition inspires a number of students to boisterous engagement.

$F(x)$ has been played and refined over two semesters, and its use is exemplified in a supplemental video. Its use falls right at a time when the students are beginning to feel overwhelmed with a formalization that is completely new to them. The board was designed with Adobe Illustrator and printed on white 11 x 17 paper. The cards were made with LTEX on colored cardstock and cut by hand. 


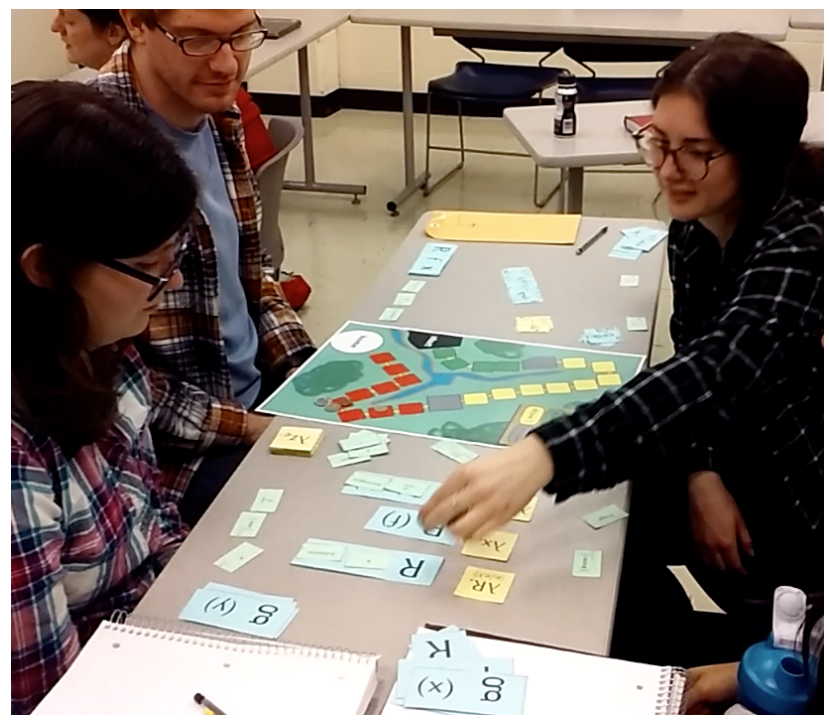

Figure 2: Students playing $f(x)$

2.2. DEVELOPED, NEEDS REFINING: Eventuality. A second game made for the semantics course is Eventuality, which concerns verbal temporal semantics. Students gain points by working out the Vendlerian categories of lexical aspect/Aktionsart for predicates that are built out of a VP card and a Determiner card.

The conceit of this game is that the players are trapped in a dungeon and must escape using semantics. Again, the board offers the rules and turn-taking steps for easy reference. Players earn points by testing predicates and producing sentences, and moving to the end of the board. Each game takes around 30 minutes.

The game exemplifies the design principles in clear ways, but not as successfully as $f(x)$.

1. Player Interaction The players are paired or teamed, so they must play cooperatively and help each other. They must also play competitively by surveilling opponents to ensure that they are doing the exercise properly, and by selecting the determiner cards they must use.

2. Process Training The students walk through Aktionsart tests for stativity, telicity, and duration. They make judgments and concoct sentences using the right tense, aspect, and predicate.

3. Randomization The predicates and determiners come from cards, so the problem set is different every time and constantly changing. Sometimes students run all the tests, other times they only need one, and sometimes they cannot run the tests at all. The required tense and aspect come from the dice, and sometimes interfere with the predicate and Aktionsart.

4. Entertainment This is the principle where things were hardest. There turned out to be little to no strategy, because the dice were simply too powerful. A team that rolled well 


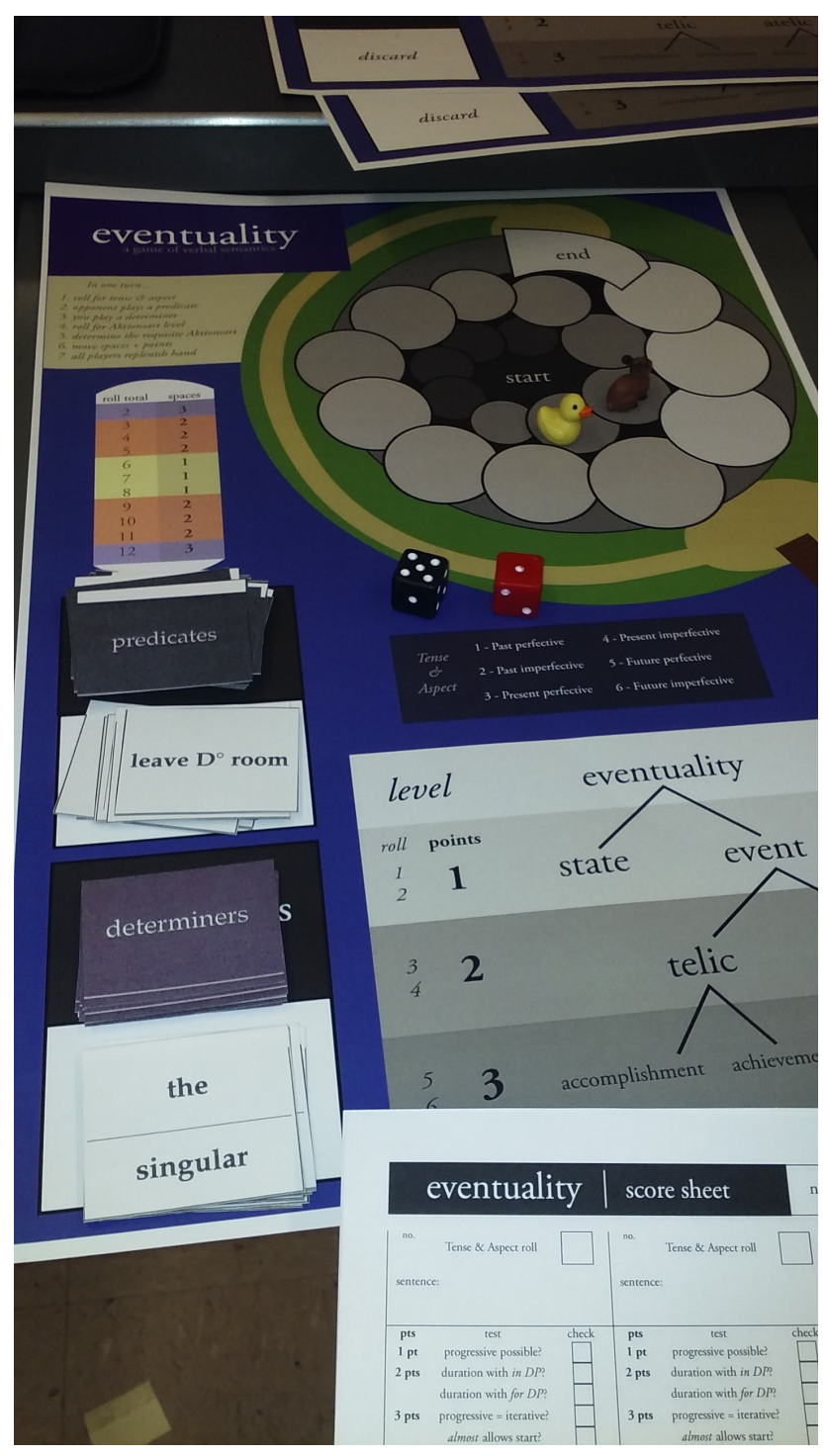

Figure 3: The gameboard and pieces for Eventuality) (printed on 11 x 17)

moved further and scored more points, running away with the game. Also, the task was the same every time, so the game was found repetitive and plodding.

The game was fairly well received beyond that, and will be refined for the next course. One key flaw was sentence production- this is too open-ended for a strict game like this. Instead, answer-formation will be used next time; compare Cards Against Humanity's card selection to Balderdash's definition creation. Another improvement will be to turn one of the players against the others as the dungeon guard, to check for success and to offer a foil for the escaping students. Also, the version will include incorporate strategy, by setting 'lock patterns' that some Aktionsart types unlock but not others. It will also set a race against time, as each 
wrong answer or failed unlocking will lead the guard closer and closer.

2.3. In DEVElopMenT: Parameters. Parameters is a game that involves the basics of syntactic analysis, largely based on the Principles and Parameters approach developed in Carnie's (2013) Syntax: A Generative Introduction. Clearly this is meant for a course in generative syntax.

Parameters is a four-player game where players play as partners. The conceit is that players are on research teams, and the goal is to be the "research team" that has theoretical analyzed the most languages when the game is over. There are two main decks: player cards (which contain a mix of Parameter Cards and Action cards) and Language Cards. There is a common tableau of languages (generally three, but this may be manipulated by Action Cards) on which all players may play Parameter Cards. To claim a Language Card, a pair must each play an appropriate Parameter Card on the Language Card. Thus, there is a blind element to the game where partners are trying to guess which language would be best to play on. Action cards allow players to interact with game rules in various ways, including viewing other players' hands, replacing Language Cards from score piles, drawing additional Language Cards to the tableau, and so forth. The game ends when a Language Card needs to be drawn and the deck is empty.

The game illustrates all four of the design elements:

1. Player interaction Player interaction is developed in two ways in this game. First, because it is a blind partner game the players need to find other ways toc ommunicate with each other within the rules to be successful. Second, the Action Cards create a large degree of player interaction allowing players to view each other's cards, steal cards, change cards in the tableau and so forth.

2. Process Training Because there is not a speed element, Players may consider their Parameter Cards closely and try to match them to appropriate languages. Players do need some familiarity with the syntactic parameters and structure to play, so it cannot introduce these skills.

3. Randomization Every instance of play will involve different combinations of Language, Parameter, and Action cards, which makes a random play space. This further reinforces the skills in (2) by creating unique combinations of syntactic examples and parameters for learners to match.

4. Entertainment Much of the entertainment of the game is driven through the player interaction described in (1) and the race element of the game.

\section{Discussion.}

3.1. GAMING IN THE LINGUISTICS CLASSROOM AND BEYOND. Unlike many other fields, Linguistics lacks a variety of commercially available, classroom-usable games. Fields like His-tory, Chemistry and many others have a deep variety of games available at a variety of aca-demic levels, gaming complexity, subject complexity, and so forth-most of these games are targeted primarily at the hobbyist market, but the educational market as a secondary considera-tion. 
The game publisher Thorny Games currently offers two commercially available games that are directly influenced by linguistic content: Dialect: A Game about Language and How it Dies and Sign: A Game about Being Understood. However, these games both require significant investments in rule-learning and playing time due to their complexity. Thus, they are not wellsuited for most classroom environments. However, they are very useful for outreach activities with active hobbyist communities, Linguistics Club activities to maintain enthusiasm for the subject, and other similar endeavors.

3.2. Developing FAmiLiar GAMES. Some linguists have adapted previously existing commercial games for linguistics audiences. Cascadilla Press and Nathan Sanders (U. Toronto), likely among many others, have developed adaptations of familiar and popular games for the linguistics classroom and similar settings. These games are adaptations (sometimes loosely so) games like Scrabble (IPA Crossword, Cascadilla), Bingo (IPA Bingo, Cascadilla), Battleship (IPA Hunt, Sanders), Crazy Eights (IPA Discard, Sanders). Such games are freely available (and in the case Cascadilla available for purchase on high quality components).

These games have several advantages compared to the developed games discussed in this short paper: first, because of their general, popularity and familiarity there is not a need for long rules explanation and familiarization-nor are players likely to become frustrated because they do not understand how to play. Several of these games are also fairly easy to scale to large groups (IPA Bingo being a very good example). The chief disadvantage is that they are primarily focused on the same skill: making memorization of the IPA fun. Thus, the lack of rules complexity becomes a bit of a double-edged sword, as learns become more comfortable with the IPA the appeal of many of these games diminishes; however, these games still may serve a vital role in many linguistics pedagogical contexts.

3.3. Motivating STUDENTS. As with any exercise, student buy-in is crucial for success. With games that are supposed to be fun, this buy-in is even more crucial. Several methods of enticing students could be used. Do the students win actual rewards for playing or winning?Bonus points or other rewards might be offered, but we find that sometimes students are happy to try the new kind of exercise with no prodding or enticement. We have used these games for advanced courses, where students are generally majors with strong intrinsic motivation. Can games like these be used for lower levels? Also, it isn't clear if actual graded exercises could be made from these games, because assessment is hard to do in the game.

4. Conclusion. Ultimately, the point of using games in the classroom is to make process learning or memorization more fun by adding extra elements of immersion and strategy. The game format offers helpful repetition in the process or task along with a useful randomization in data, giving students training at recognizing phenomena off the written page.

\section{References}

Botturi, Luca \& Christian Loh. 2009. Once upon a game: Rediscovering the roots of games in education. In C. Thomas Miller (ed.), Games: Purpose and Potential in education. 1-22. Amsterdam: Springer. https://doi.org/10.1007/978-0-387-09775-6 1.

Carnie, Andrew. 2013. Syntax: A generative introduction. New York: Wiley-Blackwell. 
Shultz Colby, Rebekah. 2017. Game-based pedagogy in the composition classroom. Computers and Composition 43. 55-72. https://doi.org/10.1016/j.compcom.2016.11.002. 